\title{
EDITORIAL
}

\section{DOS PLANES MUNDIALES PARA NO MORIR DE ÉXITO A CAUSA DE UNA INFECCIÓN}

\author{
Cristina Pérez Andrés
}

Comité de redacción de la Revista Española de Salud Pública.

\begin{abstract}
En los últimos años del siglo diecinueve nadie habría creído que los asuntos humanos eran observados aguda y atentamente por inteligencias más desarrolladas que la del hombre y, sin embargo, tan mortales como él; que mientras los seres humanos se ocupaban de sus cosas eran estudiados quizá tan a fondo como el sabio estudia a través del microscopio las pasajeras criaturas que se agitan y multiplican en una gota de agua. Con infinita complacencia, la raza humana continuaba sus ocupaciones sobre este globo, abrigando la ilusión de su superioridad sobre la materia. Es muy posible que los infusorios que se hallan bajo el microscopio hagan lo mismo.
\end{abstract}

La guerra de los mundos. HG Wells

En 1898 se publicó en el Reino Unido la novela de ciencia ficción La guerra de los mundos $^{1}$, de Herbert George Wells. Su argumento trata de la invasión de la Tierra por alienígenas procedentes de Marte en los primeros años del siglo XX. Los marcianos fueron vencidos después de tres semanas de invasión, pero no por los seres humanos sino por organismos de tamaño microscópico que, al contrario que los primeros, no practican ni la filosofía ni la ciencia, es decir no tienen desarrollos tecnológicos. Los marcianos murieron a causa de las bacterias, contra las que no tenían inmunidad.

Durante la $68^{\mathrm{a}}$ Asamblea General de la Organización Mundial de la Salud, celebrada en Ginebra el pasado 26 de mayo de 2015, se abordaron dos preocupantes puntos sobre las enfermedades infecciosas, la resistencia a los antimicrobianos y la vacunación ${ }^{2}$.

En esta última Asamblea se aprobó el Plan de Acción Mundial sobre la Resistencia a los Antimicrobianos ${ }^{3}$, que en particular hace hin- capié en los antibióticos, el cual se plantea como objetivos mejorar la sensibilización y la comprensión de la resistencia a los antimicrobianos, reforzar la vigilancia y la investigación, reducir la incidencia de las infecciones, optimizar el uso de los antimicrobianos y asegurar inversiones sostenibles para contrarrestar las resistencias.

Siglo y medio después de que Louis Pasteur elaborara su Teoría germinal de las enfermedades infecciosas, de que Joseph Lister descubriera los antisépticos, de que Semmelweis obligara a los obstetras que atendían a las parturientas en el hospital de Viena a lavarse las manos y 87 años después de que Alexander Fleming descubriera el primer antibiótico, la resistencia a estos fármacos desarrollada por los gérmenes patógenos es en la actualidad una de las principales amenazas para la salud humana y animal e incluso para la salud del planeta. La tuberculosis ultrarresistente se ha detectado en 84 países $^{4}$, las infecciones gonocócicas no tratables podrían provocar un aumento de las tasas de enfermedad y 
defunción, lo que implicaría un retroceso de los logros alcanzados en el control de esta infección de transmisión sexual ${ }^{4,5}$, y las enfermedades debidas a Klebsiella pneumoniae ${ }^{5}$ pueden ser muy graves incluso mortales porque sus agentes causales ya no son sensibles al tratamiento con los antibióticos y no existe alternativa terapéutica para las personas que las padecen.

Durante la Asamblea todos los gobiernos se comprometieron a tener su propio Plan Nacional de Acción para mayo de 2017, el cual debe abarcar el uso de antimicrobianos en la salud humana así como en la salud animal y en la agricultura.

En España el Plan estratégico y de acción para reducir el riesgo de selección y diseminación de resistencias a los antibióticos ${ }^{6}$ fue aprobado por el Consejo Interterritorial de Salud en 2013, tras la identificación, por parte del Consejo de la Unión Europea, el Parlamento Europeo, la Comisión Europea y sus Agencias [European Medicine Agency (EMA), European Centre for Disease Prevention and Control (ECDC), Heads of Medicines Agencies (HMA) y la European Food Safety Authority (EFSA)] de la necesidad de establecer una estrategia común europea para valorar y afrontar el problema del desarrollo de resistencias a los antimicrobianos En él se afirma que son numerosos los datos que urgen a emprender acciones para combatir las resistencias a los antimicrobianos así como que a causa de ellas se ponen en riesgo los logros de la medicina moderna. Sin antibióticos eficaces para la atención y prevención de las infecciones, se vería comprometido el éxito de tratamientos como el trasplante de órganos, la quimioterapia y la cirugía mayor. Volveríamos a lo que los cirujanos del siglo XIX conocían como fiebre traumática ${ }^{7}$.

La gravedad de la situación ha llevado a que Naciones Unidas, a través de sus diferentes agencias [Organización de las Naciones Unidas para la Alimentación y la Agricultura (FAO), la Organización Mundial de Sanidad Animal (OIE) y la Organización Mundial de la Salud (OMS)] haya elaborado y publicado numerosos documentos, informes, reflexiones y directrices destinadas a promover el uso prudente de los antibióticos.

También durante la Cumbre UE-EEUU, el 3 de noviembre de 2009, se decidió crear el Trans Atlantic taskforce on antimicrobial resistance (TATFAR) 8,9 para conocimiento, información, coordinación y cooperación en el campo de las resistencias antimicrobianas. El objetivo de este grupo de trabajo es intensificar la cooperación para el uso adecuado de antibióticos en salud humana y animal, prevenir las infecciones producidas por bacterias resistentes y desarrollar estrategias para la mejora en el desarrollo de nuevos antibióticos.

El Plan de Acción Mundial sobre vacu$n a s^{10}$, segundo Plan al que hace referencia el título de este editorial, se aprobó en 2012 durante la $65^{\mathrm{a}}$ Asamblea General de la OMS con el fin de alcanzar los objetivos del Decenio de las vacunas (2011-2020). El objetivo del Plan es mejorar la salud mediante la ampliación de todos los beneficios de la inmunización a todas las personas, independientemente de su lugar de nacimiento, de quiénes sean o dónde vivan. En 2020 todas las naciones deberán alcanzar una cobertura vacunal de al menos el $90 \%$ en todas las vacunas que figuren en los programas nacionales, a no ser que haya otras recomendaciones. Las enfermedades vacunables que figuran en el plan son $25^{9}$. Los objetivos generales del llamado Decenio de las Vacunas (2011-2020) son conseguir un mundo libre de poliomielitis, cumplir con los objetivos mundiales y regionales de eliminación, cumplir con los objetivos de cobertura de vacunación en todos los países, regiones y comunidades, desarrollar e introducir vacunas y tecnologías nuevas y mejoradas y superar el Objetivo número 4 de Desarrollo del Milenio de reducir la mortalidad infantil ${ }^{10}$. No obstante, el informe del Grupo de Expertos de la OMS en Asesoramiento Estratégico sobre inmunización ${ }^{11}$ advierte que el logro de los objetivos del plan es lento e irregular. En él se informa que en la actualidad un millón y 
medio de niños mueren de enfermedades vacunables y termina haciendo 18 recomendaciones sobre: la ejecución deficiente del Plan, la mala calidad de los datos y su escaso uso, la asequibilidad y suministro de las vacunas, las deficiencias de la integración básica y las situaciones que trastornan la vacunación ${ }^{15}$. Este último punto hace referencia a un aspecto sumamente importante y que no se puede obviar: que la OMS amplíe las directrices existentes sobre la inmunización en emergencias humanitarias y proporcione detalles sobre la forma de conservar los servicios de vacunación sistemática y de otro tipo a pesar de los trastornos que traen aparejados la guerra y las epidemias. Sin embargo en las situaciones que alteran los programas de vacunación parece dejarse en el tintero qué hacer con los niños que no son vacunados a causa de las ideas "personales" de sus progenitores y/o tutores.

El pasado 18 de junio tuvo lugar en el Ministerio de Sanidad la jornada WHO Mission. Elimination of Measles and Rubella ${ }^{16}$. Mark Muscat, de la Organización Mundial de la Salud, dijo al principio de su ponencia que estamos siendo víctimas de nuestro propio éxito, refiriéndose con ello a que el grado de inmunización conseguido con los programas de vacunación contra las enfermedades vacunables está llevando a la sociedad a disminuir el interés y la vigilancia de las vacunaciones y con ello a una vulnerabilidad que está causando brotes epidémicos de enfermedades vacunables próximas a su erradicación.

Concluyendo, es como si la lucha que los marcianos de HG Wells perdieron contra las bacterias también pudiera perderla ahora el género humano, lo que daría lugar a una nueva transición sanitaria, esta vez en sentido negativo.

Por ello debemos ser conscientes del papel que a cada persona le corresponde para que esto no suceda. Los profesionales sanitarios, desde nuestro puesto de trabajo, debemos conseguir resultados eficaces con las investigaciones, desarrollar políticas públi- cas efectivas y ejercer una asistencia sanitaria de calidad que incluya el uso racional de los antibióticos y el cumplimiento de los programas de inmunización. Y el resto de la sociedad debe hacer también un uso adecuado de los medicamentos e inmunizar contra las enfermedades vacunables a los niños que están bajo su tutela.

\section{BIBLIOGRAFÍA}

1. Herbert GW. La guerra de los mundos. Barcelona: Planeta; 1984.

2. Organización Mundial de la Salud. $68^{\mathrm{a}}$ Asamblea General de la Organización Mundial de la Salud. OMS: Ginebra; 2015

3. Plan de Acción Mundial sobre resistencias http://apps. who.int/gb/ebwha/pdf files/WHA68/A68 ACONF1sp.pdf

4. Organización Mundial de la Salud. Resistencia a los antimicrobianos. . OMS: Ginebra: 2013. Nota descriptiva No194. Disponible en: http://www.who.int/mediacentre/factsheets/fs194/es/

5.Galán Montemayor, JC, Moreno Bofarull A, BaqueroMochales F. Impacto de los movimientos migratorios en la resistencia bacteriana a los antibióticos. Rev Esp Salud Pública. 2014; Vol 88 (6): 829-837.

6. Grupo coordinador. Plan estratégico y de acción para reducir el riesgo deselección y diseminación de resistencias a los antibióticos. 2014-2018. Madrid: Ministerio de Sanidad, Servicios Sociales e Igualdad y Agencia Española del Medicamento; 2014.

7. Thorwald J. El siglo de los cirujanos. Madrid: Destino; 1972.

8. European Center for disease prevention and control. Transatlantic Taskforce on Antimicrobial Resistance (TATFAR). Disponible en: http://ecdc.europa.eu/en/activities/diseaseprogrammes/TATFAR/Pages/index.aspx

9. Center for diseases control and prevention. Trans Atlantic taskforce on antimicrobial resistance. Disponible en: http://www.cdc.gov/drugresistance/tatfar/index.html

10. Organización Mundial de la Salud. Plan de Acción Mundial sobre vacunas. OMS: Ginebra; 2012. Disponible en: http://apps.who.int/iris/bitstre am/10665/85398/1/9789243504988_spa.pdf

14. Naciones Unidas. Asamblea General. Desarrollo del milenio. Naciones Unidas: Nueva York; 2000. Disponible en: http://www.un.org/spanish/milenio/ares552.pdf 
15. Grupo de expertos de asesoramiento estratégico sobre inmunización. Informe de evaluación del plan de acción mundial sobre la vacunación. OMS; 2014. Disponible en: http://www.who.int/immunization/ global_vaccine_action_plan/SAGE_DoV_GVAP_Assessment_report_2014_Spanish.pdf

16. Muscat M. Santos JI. Presentation on global and regional status of measles, rubella and CRS, including most recent RVC conclusions. WHO Mission. Elimination of Measles and Rubella. Madrid: Ministerio de Sanidad, Servios Sociales e Igualdad; 2015. 